TP Periodica Polytechnica Civil Engineering

61(3), pp. 498-504, 2017

https://doi.org/10.3311/PPci.8858

Creative Commons Attribution (i)

RESEARCH ARTICLE

\section{Comparison of Flexural Performance of Lightweight Fibre-reinforced Concrete and Normalweight Fibre- reinforced Concrete}

\author{
Ahsan Ali $^{1 *}$, Shahid Iqbal ${ }^{1}$, Klaus Holschemacher ${ }^{1}$, Thomas A. Bier ${ }^{2}$
}

Received 30 November 2015; Revised 29 January 2016; Accepted 03 May 2016

\begin{abstract}
Current study encompasses comparison of flexural tests results of Normalweight Fibre-reinforced Concrete (NWFC) and Lightweight Fibre-reinforced Concrete (LWFC) beam specimens. Fibres are known for their positive effect on crack control, better post-cracking behaviour under flexure and for enhancing toughness. These improvements, however, come at the expense of degraded workability. Using lightweight aggregates of regular shape instead of heavier, irregular and rough textured normalweight aggregates can address the issue of poor workability of concrete besides other advantages that it will bring along with. Replacing normalweight aggregate with lightweight aggregate also has its demerits and in most cases under similar testing environments lightweight concrete has lower strength results. This paper covers evaluation of flexural performance for both LWFC and NWFC having similar compressive strength class. For this purpose 24 beams $150 \times 150 \times 700 \mathrm{~mm}$ in dimensions were tested under flexure. For a fair comparison, it was made sure that both the concretes (LWFC and NWFC) at every fibre volume fraction (0, $0.25,0.5$ and $0.75 \%)$ fell under the same strength class.
\end{abstract}

\section{Keywords}

lightweight concrete, expanded clay, fibres, toughness, flexure

\footnotetext{
${ }^{1}$ Department of Civil Engineering

University of Applied Sciences (HTWK)

Karl-Liebknecht-Strasse 132

D-04277 Leipzig, Germany

${ }^{2}$ Institute of Ceramics, Glass and Construction Materials

Technical University Freiberg,

D-09599, Freiberg, Germany

* Corresponding author, e-mail: ahsanone@gmail.com
}

\section{Introduction}

There are numerous advantages of using fibres in different types of structural concrete. Role of fibres for crack control, toughness, and ductility improvement and as a substitute to traditional reinforcement in particular cases is well acknowledged [1]. Fibre content or fibre volume fraction for concrete is dictated by the purpose any structure made of such concrete has to serve. Fibre volume fraction $\left(\mathrm{V}_{\mathrm{f}}\right)$ less than $1 \%$ are used for reducing shrinkage cracks, whereas greater volume fractions are intended for enhancing modulus of rupture of specimens and for producing composites having deflection hardening and strain hardening properties [2]. Such concretes, with higher fibre contents, and enhanced properties come at the cost of degraded workability and increased material costs, and are also not considered labour friendly, primarily because of effort and attention requirements at site.

Effect of addition of fibres, in quantities of low volume fraction $\left(\mathrm{V}_{\mathrm{f}}<1 \%\right)$, and lower to medium volume fraction $\left(\mathrm{V}_{\mathrm{f}}<2 \%\right)$ on mechanical properties of concretes has been extensively investigated, and in most cases specific concrete with different fibre types or geometry was the focus. Iqbal et al. [3] for example used micro steel fibres in high strength lightweight self-compacted concrete for evaluation of mechanical properties. His results of flexural beam tests show more than $65 \%$ improvement in flexural strength at $0.75 \%$ volume fraction of fibres. Kim et al. [4] observed deflection hardening behaviour for specimens under flexure at fibre volume as low as $0.4 \%$. He achieved this behaviour by incorporating chemical admixtures and using high strength concrete. Test results of experimental work by Adyin [5] also reported similar behaviour for normal strength concrete beam specimens made without using any chemical admixtures at $0.75 \%$ fibre volume fraction. For low volume fraction of fibres Soutsos et al. [6] reported deflection softening behaviour for concrete having compressive strength of $32 \mathrm{MPa}$ and observed higher flexural toughness values when steel fibres were used in combination with synthetic fibres.

All of these studies reported results for specific types of concrete with different fibre geometry and type and suggest that it is possible to obtain better flexural behaviour at lower fibre 
content. Under similar testing environment, at low volume fraction of fibres and for the same concrete strength class, what performance difference exists between LWFC and NWFC, when tested in flexure, however is not extensively reported.

\section{Flexural Performance Indicators}

Performance of LWFC and NWFC beams under flexure is evaluated by first peak strength, energy absorption capacity (toughness), and residual capacity. Fiber reinforced concrete specimens can attain multiple peak load values under flexure depending upon the quantity of fibers added to the matrix. The first peak strength $\left(f_{1}\right)$ is the flexural strength of specimens calculated at first peak load $\left(F_{1}\right)$ using Eq. (1). It is also termed as modulus of rupture as it characterizes the point of onset of the first crack where load-deflection curve has zero slope.

$$
f=\frac{F l}{b d^{2}}
$$

For Eq. (1), $F$ is flexural load, $f$, the corresponding flexural capacity, and $b, d, l$ are the width, depth and clear span of beam specimens.

Flexural toughness is the measure of the energy absorption capacity of specimens and can be determined by finding out the area under the load-deflection curve. ASTM [7] suggests determination of this area up to deflection of $1 / 150$ of the span length of beams. Residual capacity is the flexural strength or stress value of the damaged concrete in post cracking region, and here it is determined at deflection of $l / 600$ and $l / 150$.

\section{Experimental Program}

Experimental program involved testing of 24 beams $(150 \times 150 \times 700 \mathrm{~mm})$ under flexure using third-point loading test setup. The test setup is preferred over center point loading method [8], as the failure crack is not forced to initiate at the center of the beam where the matrix can have higher strength, rather it is allowed to arise where ever there is weak zone in maximum moment region of beam.

\subsection{Material Selection}

Material selection for both LWFC and NWFC were the same except for coarse aggregates. Expanded clay (commercially sold as Liapor 6.5), regular and round in shape and gravel as coarse aggregates were selected for lightweight and normalweight concrete mixes respectively. Due to their better performance under tensile loading over other types and shapes of fibers, hooked-end steel fibers were chosen as reinforcement for fibrous mixes. Table 1 highlights some of the properties of coarse aggregates and fibers. Quantities of cement, fiber content and superplasticizer for one type of concrete were kept very close to another type (Table 2). Ordinary Portland cement (CEM $42.1-\mathrm{N}$ ) as a binder and sand of size 0-2 $\mathrm{mm}$ with fineness modulus value of 2.8 as the fine aggregate were used. Polycaboxylate ether-based superplasticizer was incorporated for workability improvement. Figure 1 shows aggregates and steel fibers used in current experimental work.

\subsection{Test Setup}

Few of the issues while comparing the flexural performance of the LWFC and NWFC have been the norm of using different testing standards, specimen sizes and loading rates. All of these factors affect the results and therefore question on the validity of test results may arise if these are ignored. Results of a study [9] on effect of loading conditions and specimen size showed different behaviour of fibrous specimens under flexure for different loading environment and concluded that third-point loading arrangement is more appropriate for assessing flexural and toughness capacity compared to the centre-point test setup. For the current experimental program, therefore, similar testing

Table 1 Material properties

\begin{tabular}{lllll}
\hline \multicolumn{1}{c}{ Aggregates } & & \\
\hline Type & Particle size $[\mathrm{mm}]$ & Bulk density $\left[\mathrm{kg} / \mathrm{m}^{3}\right]$ & Particle density $\left[\mathrm{kg} / \mathrm{m}^{3}\right]$ & $24 \mathrm{H}$ water absorption \\
\hline Expanded clay & $2-10$ & 650 & 1190 & 14.36 \\
Gravel & $2-8$ & 1474 & 2520 & 1.48 \\
\hline & & Fibers & & Tensile strength $[\mathrm{MPa}]$ \\
\hline Shape & Length $[\mathrm{mm}]$ & Width $[\mathrm{mm}]$ & Aspect ratio & 1100 \\
\hline Hooked-end & 35 & 0.55 & 0.64 & 100 \\
\hline
\end{tabular}

Table 2 Mix design for LWFC and NWFC

\begin{tabular}{lllllll}
\hline Concrete Type & $\begin{array}{l}\text { Cement } \\
{\left[\mathrm{kg} / \mathrm{m}^{3}\right]}\end{array}$ & $\begin{array}{l}\text { Coarse } \\
\text { aggregate } \\
{\left[\mathrm{kg} / \mathrm{m}^{3}\right]}\end{array}$ & $\begin{array}{l}\text { Fine aggregate } \\
{\left[\mathrm{kg} / \mathrm{m}^{3}\right]}\end{array}$ & $\begin{array}{l}\text { Total water } \\
{\left[\mathrm{kg} / \mathrm{m}^{3}\right]}\end{array}$ & $\begin{array}{l}\text { Effective } \\
\mathrm{w} / \mathrm{c}\end{array}$ & $\begin{array}{l}\text { Superplasticizer } \\
{[\% \text { weight of cement }]}\end{array}$ \\
\hline LWFC & 360 & 472 & 772 & 205 & 0.35 & 0.5 \\
NWFC & 350 & 884 & 955 & 180 & 0.45 & 0.5 \\
\hline
\end{tabular}

$* \mathrm{f}_{\mathrm{v}}=0,20,40,60 \mathrm{~kg} / \mathrm{m}^{3}=0,0.25,0.5,0.75 \% \mathrm{~V}_{\mathrm{f}}$ 


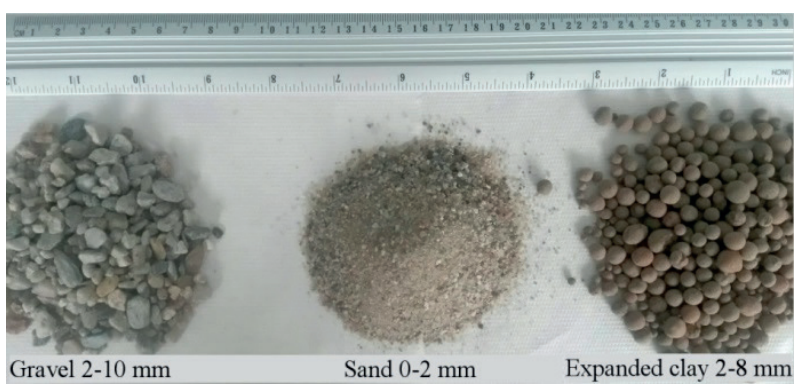

(a)

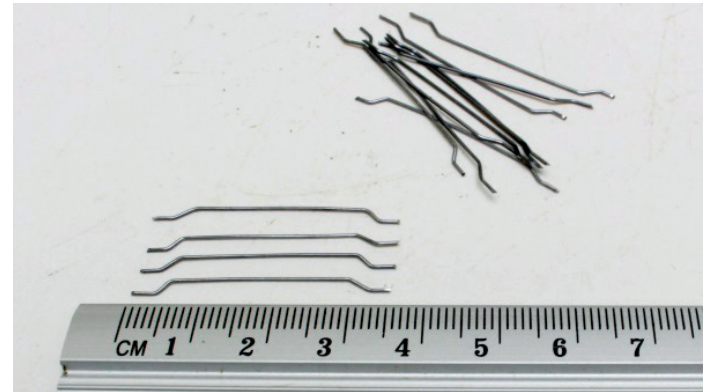

(b)

Fig. 1 (a) Aggregates with corresponding size ranges; (b) Hooked-end steel fiber

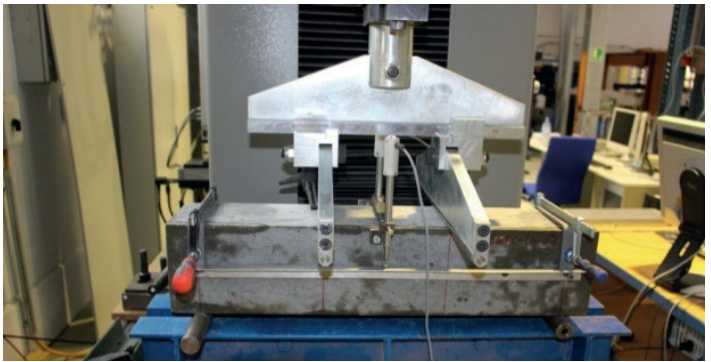

(a)

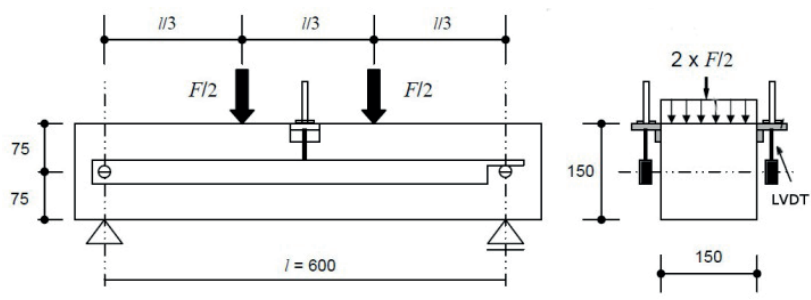

(b)

Fig. 2 (a) Specimen ready for testing (b) Details and dimensions of specimens

environment, specimen size, and material selection (except coarse aggregates) were ensured.

Beams were tested using deflection controlled machine with third-point loading arrangement (Fig. 2). Loading rate was increased in steps with increasing deflection as per ASTM [7] guidelines. Two Linear Variable Displacement Transducers (LVDTs) were used - each one on the longitudinal side of the beam for recording center point deflection and corresponding loading. Loading of specimens continued until they broke or achieved net deflection of $4 \mathrm{~mm}$.

\section{Results}

\subsection{Concrete Properties}

Before testing beams for flexure, compressive strength of the concrete was determined by testing the cubes of size 150 x 150 x $150 \mathrm{~mm}$. Table 3 presents results of compression test along with fresh concrete density and slump flow values. Compression test and workability tests were performed using German DIN standards [10], [11]. These tests were preferred over other methods due to their ease, simplicity and application. For example, German DIN standard uses same testing method for workability measurement of concretes with or without fibers, making it suitable to quantify the effect of fibers. For structural lightweight concrete, equilibrium concrete density should not be more than $1920 \mathrm{~kg} / \mathrm{m}^{3}$ and compressive strength not less than $17 \mathrm{MPa}$ [12]. It can be seen that for every respective fiber volume, difference between the compressive strength of LWFC and NWFC is less than 5 MP and at the same time satisfy the fresh density requirement. This objective was achieved through extensive trial mixes so that a rational comparison of flexural performance could be made between the two types of concretes at every fiber dosage. Because of higher particle density of coarse aggregates, workability of NWFC was affected to the lower extent compared to LWFC. However, at every fiber dosage, LWFC achieved better workability than NWFC due to higher total amount of water available during mixing and also because of regular, round shape of aggregates that helped concrete to achieve better spread values. Fibers are believed to increase the density of concrete [13], fresh concrete density of both the concretes increased with addition of fibers (except for NWFC - 20) but the rate of increase in density decreased.

Both concretes achieved maximum compressive strength at $0.5 \%\left(40 \mathrm{~kg} / \mathrm{m}^{3}\right)$ volume fraction of fibers. Fiber content higher than this level seems to have started disturbing the packing of matrix resulting in decrease of compressive strength. Similar trend was observed by Karatas and Gunes [14] who concluded that addition of steel fibres had variable effect on the compressive strength of concrete.

\subsection{Flexural Performance}

\subsubsection{First peak strength, $f_{1}$}

First peak strength characterizes the point of onset of the first crack; hence stress at this level is also called first cracking stress. Flexural strength values at first peak loads $\left(F_{l}\right)$ for all specimens are tabulated in Table 4. Although, it appears to be as if fibers have increased the flexural strength at this load value, fluctuation of values with compressive strength suggests that not fibers, rather compressive strength is the key reason for this increase. 
Table 3 Concrete Properties

\begin{tabular}{ccccc}
\hline $\begin{array}{c}\text { Fiber Content } \\
{\left[\mathbf{k g} / \mathbf{m}^{\mathbf{3}}\right]}\end{array}$ & Concrete Type & $\begin{array}{c}\text { Fresh Concrete Density } \\
{\left[\mathbf{k g} / \mathbf{m}^{\mathbf{3}}\right]}\end{array}$ & $\begin{array}{c}\text { Compressive strength } \\
{[\mathbf{M P a}]}\end{array}$ & $\begin{array}{c}\text { Slump flow } \\
{[\mathbf{m m}]}\end{array}$ \\
\hline \multirow{2}{*}{0} & Lightweight & 1716.73 & 37.98 & 440 \\
& Normalweight & 2243.83 & 42.90 & 390 \\
\multirow{2}{*}{20} & Lightweight & 1782.10 & 39.98 & 39.13 \\
& Normalweight & 2213.33 & 45.98 & 390 \\
40 & Lightweight & 1822.33 & 46.20 & 390 \\
& Normalweight & 2270.60 & 41.37 & 390 \\
60 & Lightweight & 1831.00 & 31.26 & 365 \\
\hline
\end{tabular}

Table 4 Flexural performance indicators

\begin{tabular}{|c|c|c|c|c|c|c|c|}
\hline Specimen & $\begin{array}{c}\text { Fiber content } \\
{\left[\mathrm{kg} / \mathrm{m}^{3}\right]}\end{array}$ & $\begin{array}{c}l \\
{[\mathrm{~mm}]}\end{array}$ & $\begin{array}{c}F_{1} \\
{[\mathrm{kN}]}\end{array}$ & $\begin{array}{c}f_{l} \\
{[\mathrm{MPa}]}\end{array}$ & $\%$ increase & $\begin{array}{c}\delta_{1} \\
{[\mathrm{~mm}]}\end{array}$ & $\begin{array}{c}T \\
{[\text { Joules] }}\end{array}$ \\
\hline \multirow{4}{*}{ LWFC } & 0 & \multirow{4}{*}{600} & 19.31 & 3.48 & 0.00 & 0.098 & 1.21 \\
\hline & 20 & & 21.55 & 3.87 & 11.21 & 0.104 & 41.26 \\
\hline & 40 & & 25.97 & 4.68 & 34.48 & 0.33 & 71.58 \\
\hline & 60 & & 22.09 & 3.93 & 12.93 & 0.108 & 67.01 \\
\hline \multirow{4}{*}{ NWFC } & 0 & \multirow{4}{*}{600} & 23.04 & 4.14 & 0.00 & 0.098 & 1.28 \\
\hline & 20 & & 26.42 & 4.70 & 13.53 & 0.104 & 52.69 \\
\hline & 40 & & 28.60 & 5.15 & 24.4 & 0.08 & 86.25 \\
\hline & 60 & & 28.26 & 5.04 & 21.74 & 0.12 & 93.94 \\
\hline
\end{tabular}

Note: Values are average of 3 specimens

$\delta_{I}=$ Beam deflection at first peak load

This observation is in agreement with the findings of Shah [15], who observed no improvement in first cracking stress for the amount of fibers used in current experimental work. Comparison of the results of LWFC and NWFC (Fig. 3) shows that maximum and the minimum difference of first peak strength is at fiber dosages of 60 and $40 \mathrm{~kg} / \mathrm{m}^{3}$ where LWFC achieved $28.24 \%$ and $10.04 \%$ respectively lesser strength than NWFC.

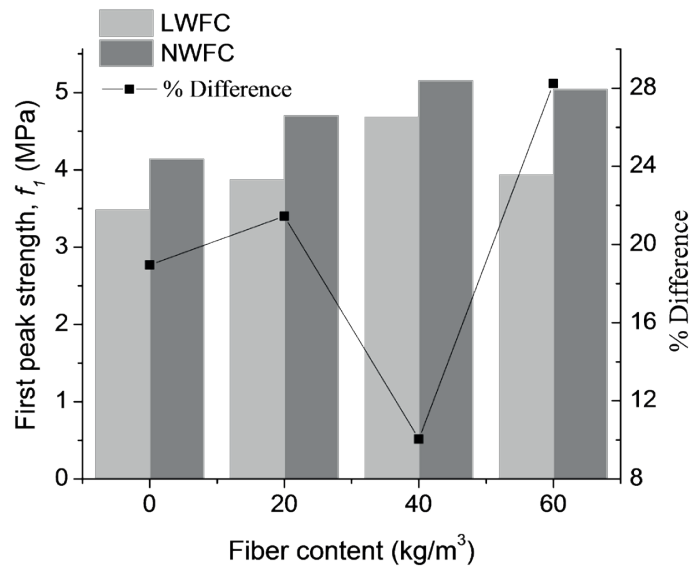

Fig. 3 Flexural strength of specimens at first peak point

\subsubsection{Toughness, $T$}

In recent years with growing security concerns, toughness is expected to become the most desired property of the concrete, especially in situations where structural elements have to withstand impact from shocks and blasts. Toughness is also highly influenced property of concrete when fibers are added to it. It characterizes material's capacity to energy absorption and is evaluated by determining the area under the load-deflection curve up to specific deflection point. Fig. 4 shows area under load deflection curves up to deflection of $4 \mathrm{~mm}(l / 150)$ along with toughness values in joules. Although LWFC achieved lower toughness values, pattern of the curves suggests that fibers had similar effect on both concretes. Poor bond of lightweight aggregates with the mortar and their lower strength under tensile loading are assumed to be the reason due to which fibers kept on slipping at reduced loading. As a result of this slippage, contribution of fibers in bridging the cracks is also affected. Failure of all the specimens occurred in the maximum moment region of beams.

As expected, presence of multiple cracks at the tensile surface was not observed at such low percentage of fibers. Although few small cracks started appearing at higher volume fraction (40 and $60 \mathrm{~kg} / \mathrm{m}^{3}$ ) of fibers, these could not progress further to compression zone, and failure occurred due to single major crack (Fig. 5). At maximum fiber content, LWFC and NWFC had toughness values 55 times and 73 times higher than their respective control specimens. Toughness values of LWFC were lower than NWFC by $5.8 \%, 27.8 \%, 20.5 \%$ and $40 \%$ at 0 , 20,40 and $60 \mathrm{~kg} / \mathrm{m}^{3}$ fiber contents respectively. 


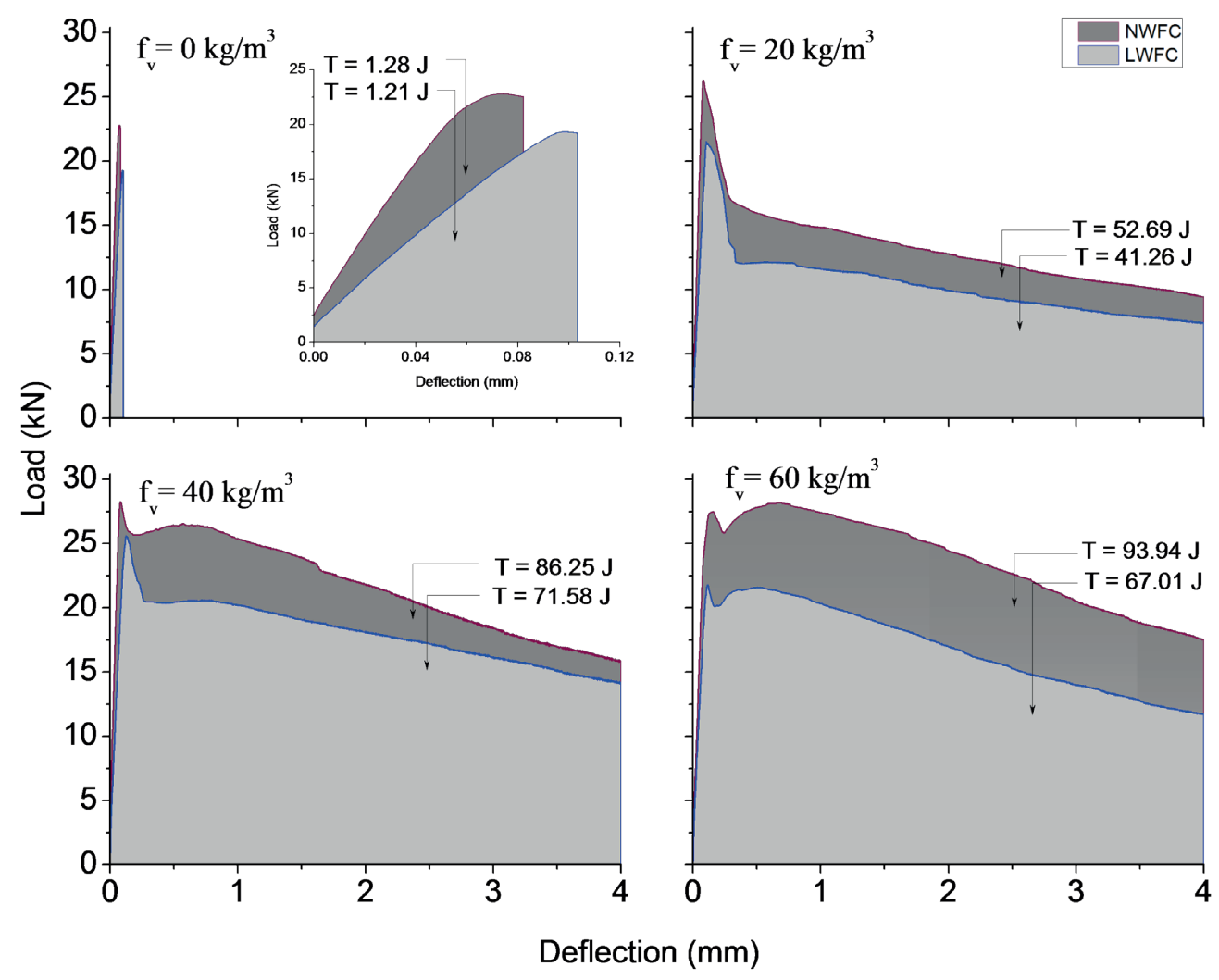

Fig. 4 Evaluation of area under load-deflection curves
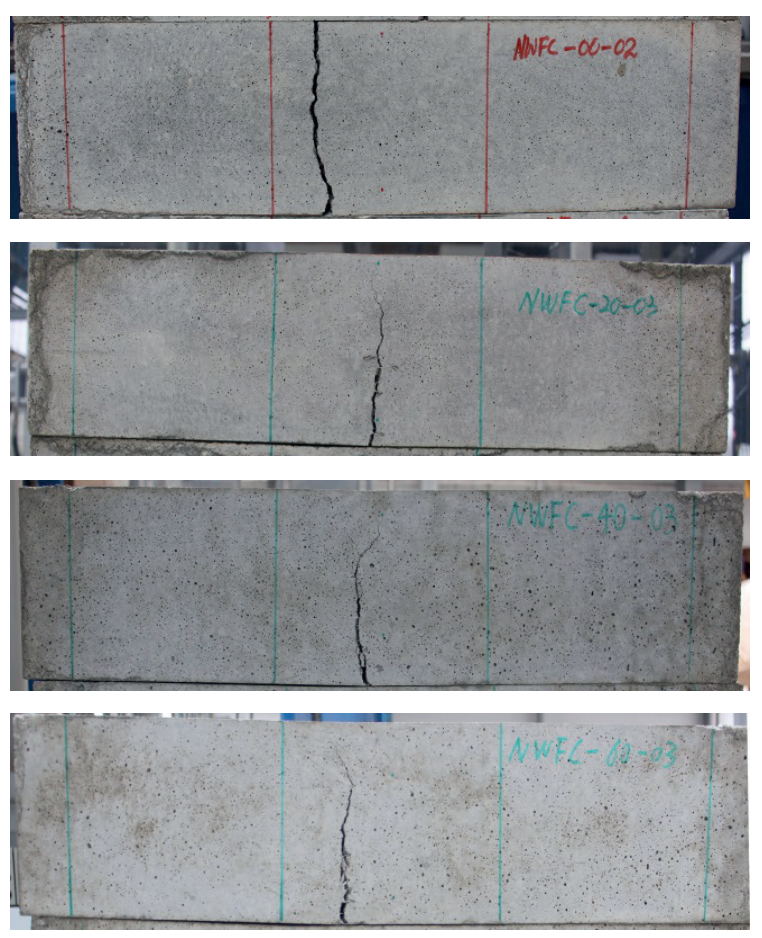

(a)
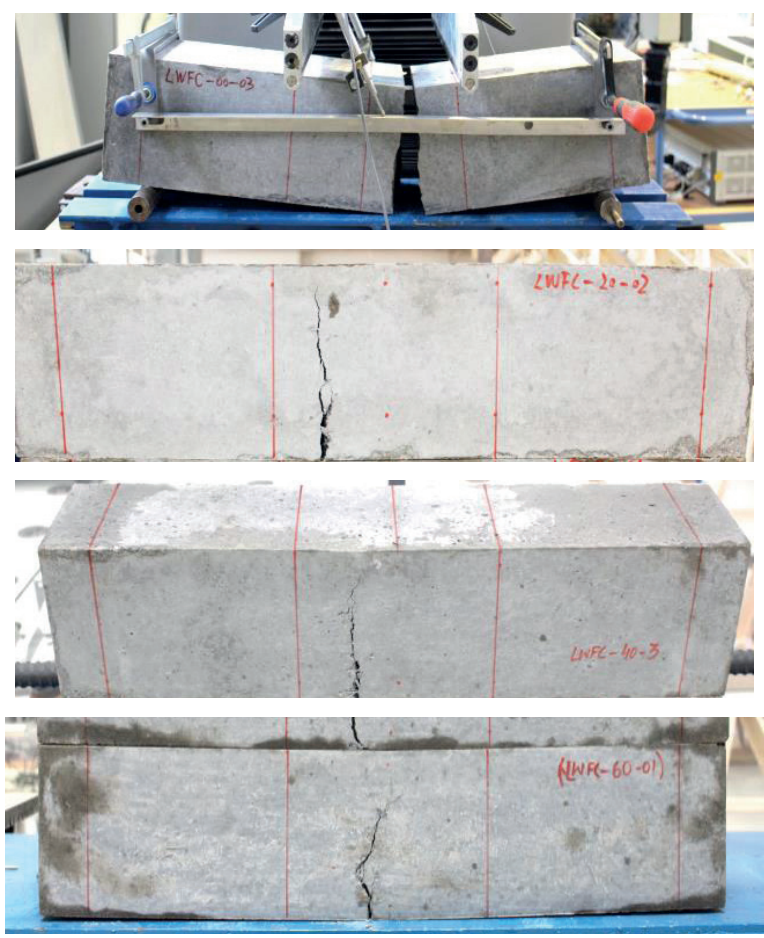

(b)

Fig. 5 Overview of specimens after testing (a) NWFC (b) LWFC

\subsubsection{Residual capacity, $\left(f_{l / 600} \& f_{l / 150}\right)$}

Post first peak performance of cracked concrete is highly dependent on the amount of fibers added to it [16]. Multiple peaks on load deflection curves started becoming prominent at fiber volume fraction of $0.5 \%\left(\mathrm{f}_{\mathrm{v}}=40 \mathrm{~kg} / \mathrm{m}^{3}\right)$. After the first crack point, load started decreasing rapidly with increasing deflection for a while and later started rising as the tensile load shifted to fibers. From this point onward, beams of NWFC with maximum fibre amount were able to regain flexural strength higher than first peak strength at higher deflection values $(0.5$ $\mathrm{mm}$ ). For lightweight concrete, the residual strength at maximum peak strength (at around $0.4 \mathrm{~mm}$ for all specimens) and the 
first peak remained almost at the same level. Residual strength of LWFC also remained lower than NWFC at all stages of flexural tests of all specimens. Fig 6 shows residual flexural strength values calculated at $1 \mathrm{~mm}\left(f_{l / 600}\right)$ and $4 \mathrm{~mm}\left(f_{l / 150}\right)$ for fiber volume of 20,40 and $60 \mathrm{~kg} / \mathrm{m}^{3}\left(0.25,0.5\right.$ and $\left.0.75 \% \mathrm{~V}_{\mathrm{f}}\right)$. Specimens of $0 \% \mathrm{~V}_{\mathrm{f}}$ could not achieve deflections higher than 0.15 $\mathrm{mm}$ and showed no residual capacity, which is typical of unreinforced beams. At volume fraction of $0.25 \%$, NWFC achieved $27 \%$ higher residual capacity than LWFC measured at deflection of $1 \mathrm{~mm}$ and $4 \mathrm{~mm}$. At similar deflection levels, difference between the two concrete became wider at maximum volume fraction $(0.75 \%)$ as the NWFC achieved residual capacity $37 \%$ and $49 \%$ higher than LWFC. Reason for the widening of this performance gap, with increasing fiber quantity, is considered to be the better synergy between stiff concrete matrix resulting from irregular, rough textured coarse aggregate and the fibers.
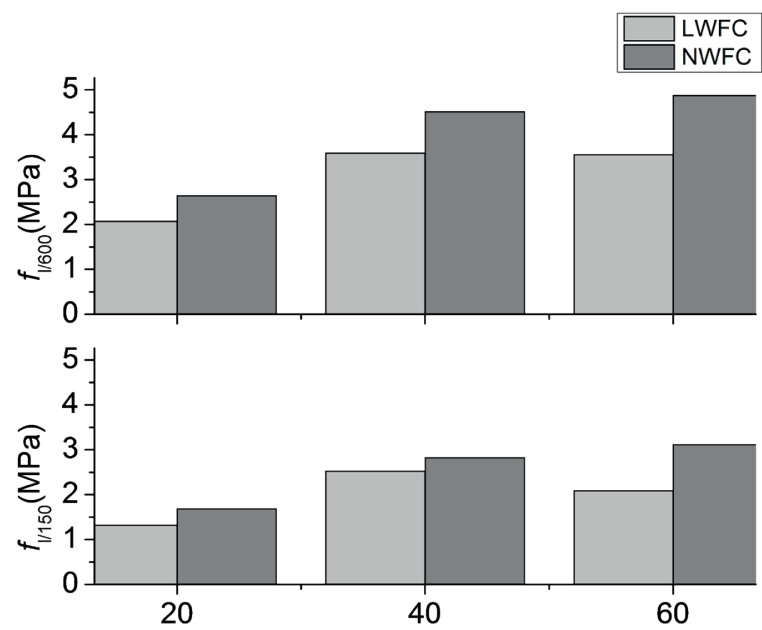

Fiber content $\left(\mathrm{kg} / \mathrm{m}^{3}\right)$

Fig. 6 Residual flexural strength of specimens

\section{Conclusions}

An experimental program for comparing the flexural performance of LWFC and NWFC was carried out. Besides flexural tests under four point loading arrangement, tests for slump flow, fresh concrete density, and compressive strength were also performed. Following conclusions from the experimental results are drawn;

At slight higher cement content, lightweight concrete is able to achieve the compressive strength similar to that of normalweight concrete at all levels of fiber dosages. Effect of fibers on the workability of lightweight concrete is more pronounced than NWFC. Slump flow values and handling during casting stage favor LWFC over NWFC.

LWFC although having similar compressive strength showed lower flexural performance than NWFC when measured by indicators of first peak strength, toughness, and residual capacity.

First peak strength of LWFC was lower than NWFC by 10 to $28 \%$.
Toughness of NWFC was higher by $40 \%$ than LWFC at the maximum volume fraction $(0.75 \%)$ of fibers. Because of fibers (at $\mathrm{V}_{\mathrm{f}}=0.75 \%$ ), specimens of LWFC after cracking were able to regain flexural strength similar to that calculated at first peak load. NWFC, on the other hand achieved higher post cracking flexural strength values.

Maximum performance difference between the two concretes was observed in terms of residual capacity measured at deflection of $4 \mathrm{~mm}$, where NWFC managed to gain $49 \%$ higher strength.

Poor flexural performance of LWFC compared to NWFC is attributed to poor bond between round shaped lightweight aggregates in LWFC against the better synergy between stiff concrete matrix of NWFC resulting from irregular, rough textured coarse aggregate and fibers.

\section{References}

[1] Ahmed, E., Legeron, F., Ouahla, M. "Steel fiber as replacement of minimum shear reinforcement for one-way thick bridge slab." Construction and Building Materials. 78, pp. 303-314. 2015. https://doi.org/10.1016/j. conbuildmat.2014.12.095

[2] Mehta, P. K., Monteiro, P. J. M. “Concrete: Microstructure, Properties, and Materials." 4th ed., McGraw-Hill, New York, N.Y., 2013.

[3] Iqbal, S., Ali, A., Holschemacher, K., Bier, T. A. "Mechanical properties of steel fiber reinforced high strength lightweight self-compacting concrete (SHLSCC)." Construction and Building Materials. 98, pp. 325-333. 2015. https://doi.org/10.1016/j.conbuildmat.2015.08.112

[4] Kim, D. J., Naaman, A. E., El-Tawil, S. "Comparative flexural behavior of four fiber reinforced cementitious composites," Cement and Concrete Composites. 30(10), pp. 917-928. 2008. https://doi.org/10.1016/j.cemconcomp.2008.08.002

[5] Aydın, S. "Effects of fiber strength on fracture characteristics of normal and high strength concrete" Periodica Polytechnica Civil Engineering. 57(2), pp. 191-200.2013. https://doi.org/10.3311/PPci.7174

[6] Soutsos, M. N., Le, T. T., Lampropoulos, A. P. "Flexural performance of fibre reinforced concrete made with steel and synthetic fibres." Construction and Building Materials. 36, pp. 704-710. 2012. https://doi. org/10.1016/j.conbuildmat.2012.06.042.

[7] “ASTM C1609 / C1609M - 12 Standard Test Method for Flexural Performance of Fiber-Reinforced Concrete (Using Beam With Third-Point Loading)." [Online]. Available from: http://www.astm.org/Standards/C1609.

[8] ACI Committee 544.2R-89: "Measurement of Properties of Fiber Reinforced Concrete," 2009.

[9] Feleko, B. "Effects of loading conditions and specimen thickness on the flexural behavior of fiber-reinforced cementitious composites." Periodica Polytechnica Civil Engineering. 58(3), pp. 279-291. 2014. https://doi. org/10.3311/PPci.7486

[10] DIN EN 12390-3 “Testing hardened concrete - Part 3: Compressive strength of test specimens; German version EN 12390-3:2009," Deutshes Institut für Normung, Berlin, 2009.

[11] DIN EN 12350-5 "Testing fresh concrete - Part 5: Flow table test; German version EN 12350-5:2009,” Deutshes Institut für Normung, Berlin, 2009.

[12] Ries, J. P., Boyle, M. J., Bremner, T. W., Burg, R. G. et al. "Guide for Structural Lightweight-Aggregate Concrete Reported by ACI Committee 213.," pp. 1-38, 2010. 
[13] Hassanpour, M., Shafigh, P., Mahmud, H. B. "Lightweight aggregate concrete fiber reinforcement - A review." Construction and Building Materials. 37, pp. 452-461. 2012. https://doi.org/10.1016/j.conbuildmat.2012.07.071

[14] Karatas, M., Gunes, A. "Engineering Properties of Self-Compacting Concrete Produced by Polypropylene and Steel Fiber." Periodica Polytechnica Civil Engineering. 59(2), pp. 95-102. 2015. https://doi. org/10.3311/PPci.7348
[15] Shah, S. P. "Do Fibers Increase the Tensile Strength of Cement-Based Matrix?.” ACI Materials Journal. 88(6), pp. 595-602. 1992.

[16] Soulioti, D. V., Barkoula, N. M., Paipetis, A., Matikas, T. E. "Effects of fibre geometry and volume fraction on the flexural behaviour of steelfibre reinforced concrete." Strain. 47(SUPPL. 1), pp. 535-541. 2011. https://doi.org/10.1111/j.1475-1305.2009.00652.x 